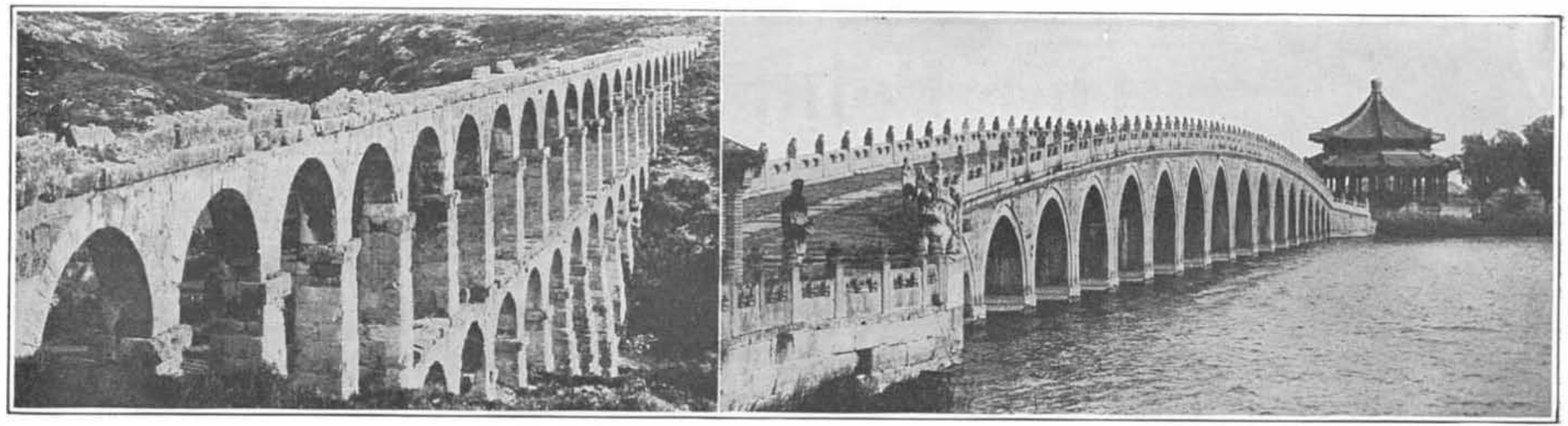

The monumental Roman aqueducts are an historical landmark. This one stands today at Tarragona, Spain
The Chinese are the earliest recorded bridge builders. This structure, built entirely of marble, has both architectural beauty and dignity

\title{
Some Aspects of Bridge Architecture
}

\section{A Bridge Should Combine Grace and Dignity With Strength and Permanence}

\section{By Dr. Eng. Gustav Lindenthal, C.E.}

"A RCHITECTURE," as defined by Ruskin, "is the raised by man for whatever uses, that the sight of them may contribute to mental health, power and pleasure." Among the prominent edifices of mankind are the great bridges. Their architecture in all countries marks in a peculiar way the progress of mankind in the art of construction, considered as an index of its civilization and culture.

It is a characteristic fact that the architecture of buildings precedes everywhere the architecture of bridges; the reason being that structures growing to height and resisting merely weight and loads are easier to plan and to build than are structures carrying weight and loads over free space. It requires of the builder greater skill and judgment to create a self-supporting stone arch or a high-arcaded aqueduct than to erect a pyramid or obelisk, a palace or spire.

Thus, the Egyptian masterbuilders were able to erect 4,000 years ago marvellous temples, of so enormous a size and of an architectural beauty so magnificent, that no structure built since then anywhere can equal them. Yet the fiat stone roofs of their gigantic halls had to be carried on columns, standing close together; for the art of bridging space with arches was unknown to them. It was also unknown to the wonderfully skillful $\mathrm{Hel}$ lenic architects. Had the ancient Egyptians or Greeks known the art of arch construction, they would have bridged the Nile as the Romans bridged the Tiber.

The Era of Bridge Architecture commences with the stone arch. The invention of the arch is usually credited to the Etruscans. Although stone arches appeared about 600 B. C., it was many years before Roman architects were bold enough to attempt stone bridges over the Tiber, the first of which were built in the first century B. C. Some of these are still in use.

The earliest forms were, of course, crude. mostly the half circle on low abutments. With increasing experience, higher and bolder arch bridges were built on piers, many in the form of long viaducts and aqueducts consisting of two and three stories of superimposed arch arcades. They were great achievements when we consider that the Roman architects had only poor equipment for laying out their work, and that the tools of their artisans and craftsmen were of the simplest kind.

What wonderful vaulted monuments these great masters, whose very names are unknown, would have created in that wealthy age, with its love of the beautiful and its exquisite sense of proportions, had these men possessed the modern accurate knowledge of the strength of materials and of mathematical statics! But such knowledge did not exist until less than 200 years ago. A few empirical rules, evolved from experience and failures, sufficed for the construction of the architectural wonders in the form of castles, great cathedrals, palaces and bridges through all the centuries, extending from ancient times to the beginning of the Renaissance. As it is, throughout Europe we find evidence of refined architectural forms in the stone arch bridges. There must have also been many fine wooden bridges; but no trace has been left of such perishable structures.

Towards the end of the sixteenth century, the opulent, art-loving Italian cities, also encouraged competition of designs for beautiful bridges. The same architects that designed their churches and palaces, designed and built bridges. From that period we have inherited the famous Rialto Bridge in Venice by An tonio da Ponte, and the beautiful elliptical stone arch bridge Ponte della Trinita in Florence by Bartolemeo Amanati. There are also a number of smaller bridges, veritable architectural gems, by the contemporary Andrea Palladino, the leader of the Italian Renaissance in architecture. The flat segmental form of arch makes its appearance; the piers receive a slimmer and more elegant form; the adjoining river shores are terraced and brought into architectural harmony with the bridge structure as a whole. Decorative sculptures commemorate historical events and give expression to the dignity of the community. The cunning workmanship of the bridge balustrades, the graceful profiles of the cornices, the imposing gates and tower entrances, all speak to us of the ambition of the masterbuilders, of the civic pride and public spirit of the people, and of their love for the beautiful and harmonious in their surroundings.

One hundred years later the leadership in artistic bridge designing went to France, where a great impulse had been given to Arts and Sciences by Louis XIV. M. Perronet was the recognized master bridge builde of that time. His designs are distinguished by elegance and stateliness of proportion and finely executed stonework. He developed the flat elliptic arch, and to him

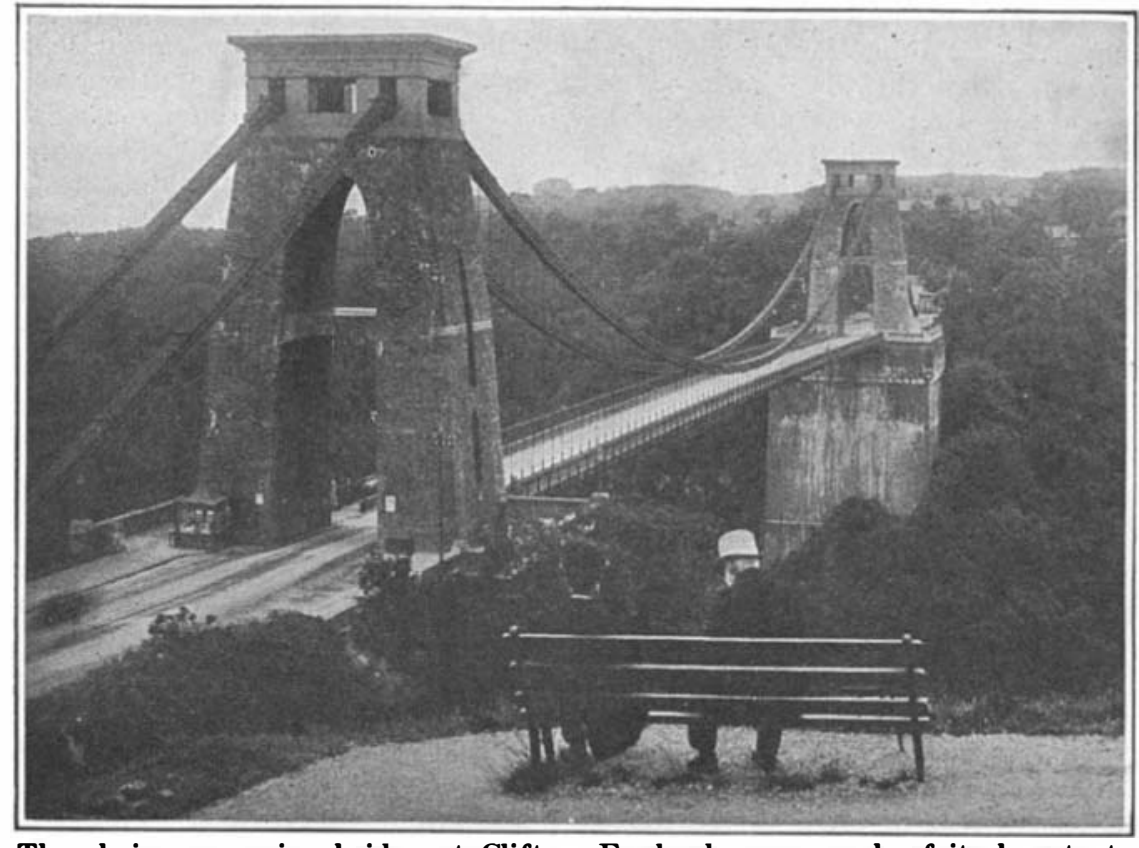

The chain suspension bridge at Clifton, England, owes much of its beauty to the massive and appropriate masonry towers we owe many beautiful stone bridges in France. The first stone bridge in St. Petersburg over the Nern was also from his designs. His method appeared also in the London Bridge. Perronet's bridges at Neuilly over the Seine and the Concord bridge in Paris will always be regarded as among the finest examples of architectuiral distinction in stone arch construction.

When iron came into use as a material for bridges about 150 years ago, it was a new material for architects. It gave birth to a new architecture, since it could be used to resist tension as well as pressure. It has obtained its most æesthetic value in the large suspension bridges built in the last one hundred years. Some elegant arch designs carrying streets and boulevards across the Seine in Paris were executed in cast iron. With iron and steel, larger spans than with stone became possible, and the way was open to a grander bridge architecture than was ever possible in stone.

With the railroads came a sweeping change in transportation, in bridge construction, and also in bridge architecture. Today the desire for aesthetic structures is struggling with utilitarianism. Few only of the large iron railroad structures have a pleasing appearance. The great majority range from poverty-stricken simplicity to downright ugliness. The new material finds its best expression in the graceful curves of the suspension bridge, in the forms of the massive or latticed beain, and in the lofty and long-span arch.

The very rapid development of the technical sciences, including statics, led, it is true, to great precision and economy in the dimensioning of bridge structures; but, unfortunately, the fact was overlooked or ignored that iron and steel are subject to corrosion and are more perishable than stone. While stone bridges will endure for ages with little care, iron bridges require painting structive elements in the air. And so it may come to pass that in the coming ages, say in the next 2,000 years, stone bridges, including the great Roman viaducts built in southern climates, where frost is not known, may still stand, with 4,000 years of life to their credit, as monuments of a past great civilization, while nothing may remain of the great iron and steel structures of the present day, but the stone piers and abutments, on which they were reared. Unless care is taken to build iron bridges in more durable form, and exercise continuous vigilance in their maintenance, they will surely be past their usefulness at some future time when our tall buildings of the skyscraper type, in which the steel frames are protected against corrosion, will still be giving good service to mankind.

The necessity of preserving large and costly iron and steel bridges against early decay should lead to a special type of protective architecture in bridges, as the same necessity has already done in the construction of steel-framed buildings. In fact, the beginning has already been made with smaller steel structures, by covering them with a coating of cement mortar. 


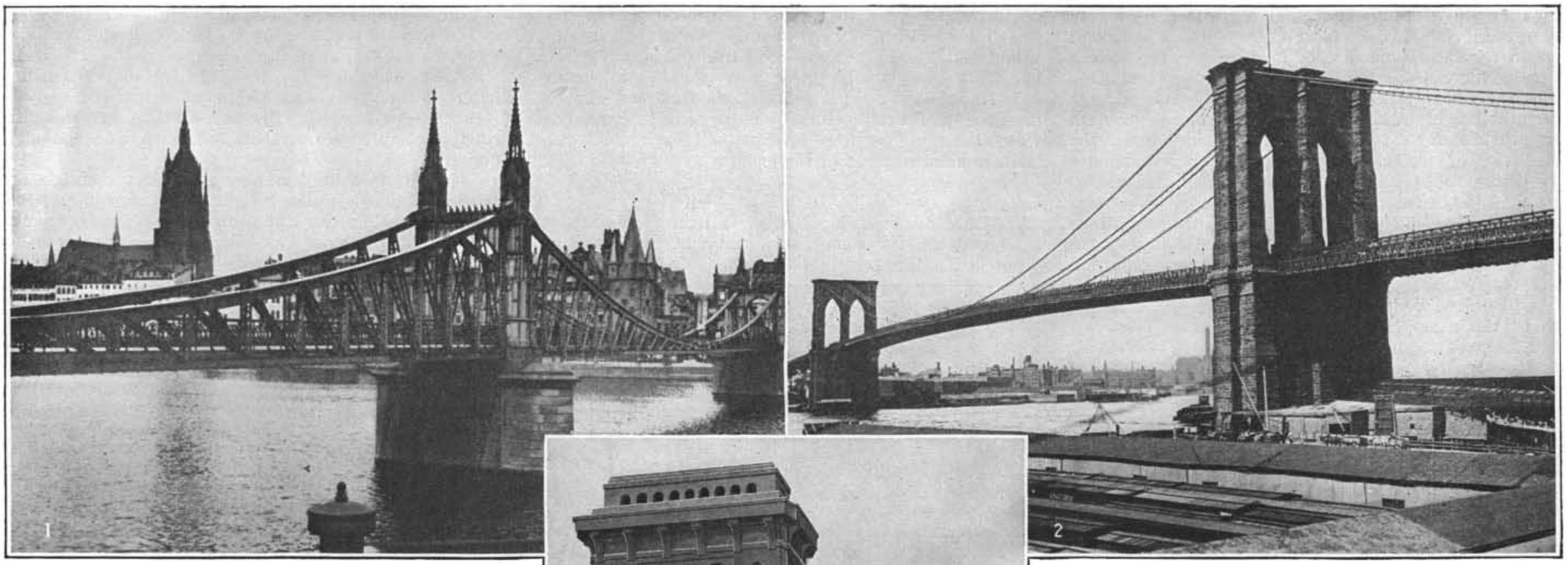

But this is a mere substitute for paint and does not promise a sure degree of durability, since the coating is liable to crack off. Pleasing architectural effects are not possible with such mongrel combinations, nor with the new material, "armored concrete," where it follows the lines of a framed steel or wood structure.

Concrete reinforced by steel offers great architectural possibilities for bridges. It is, indeed, the best material for masonry bridges of long span; but its most useful function in bridge construction should always be in the form in which the Romans, the inventors of concrete, used it, namely, in the form of an arch. IVith modern theory and resources, masonry arch bridges can be built of much longer spans than the Roman and Italian masterbuilders dared to use. Their longest span, built at the end of the fourteenth century over the Adda in Italy, attained a length of 251 feet Concrete lends itself readily to moulded forms of decoration, although this can never attain that distinction which the stonecutter's art can produce in stone.

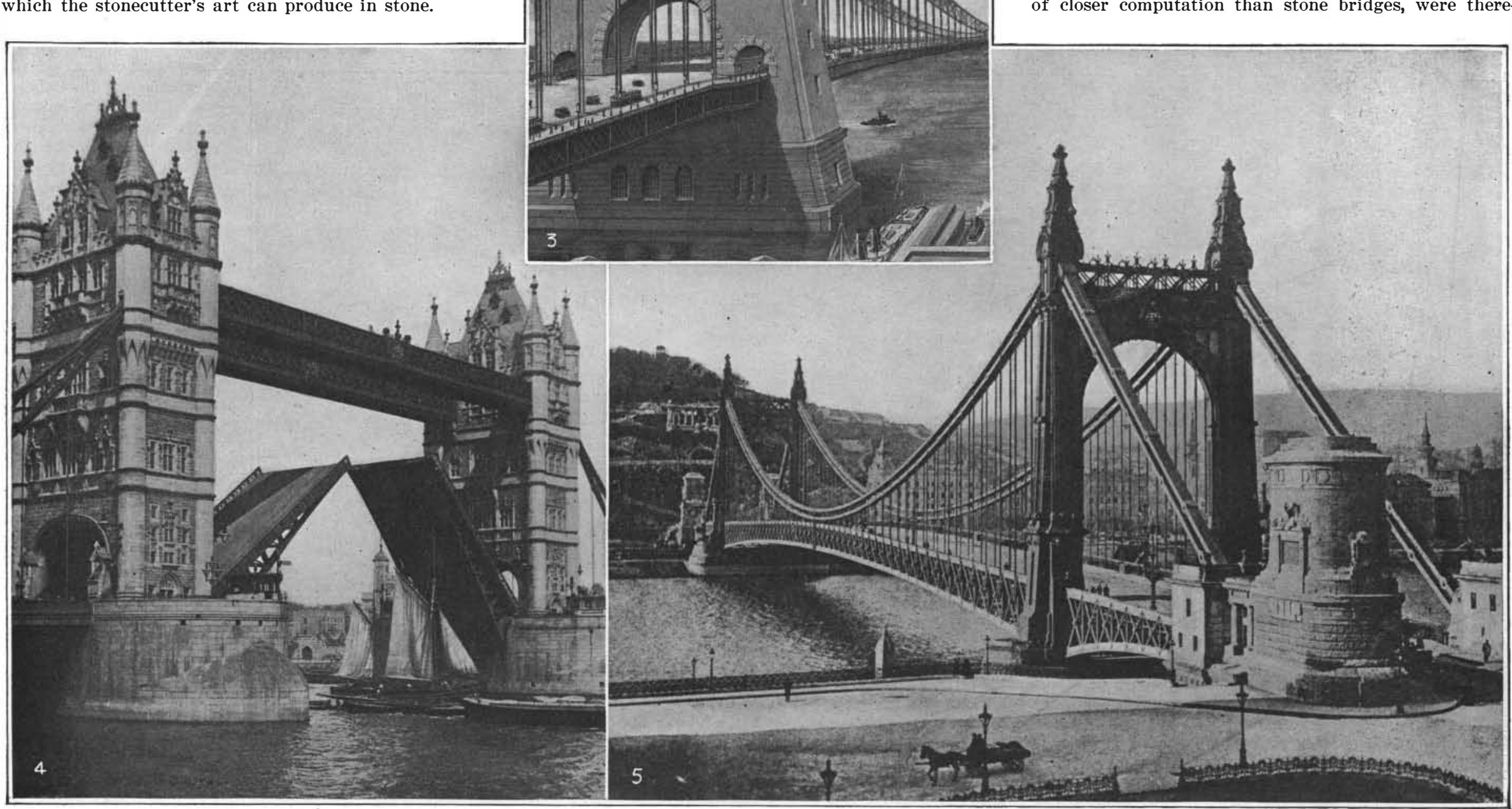

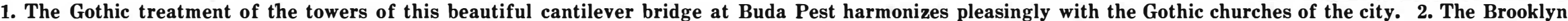

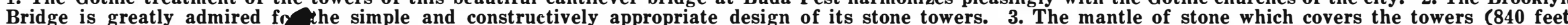

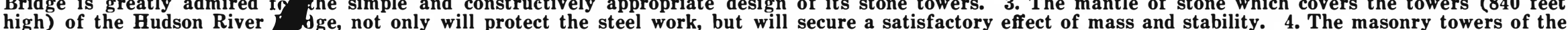

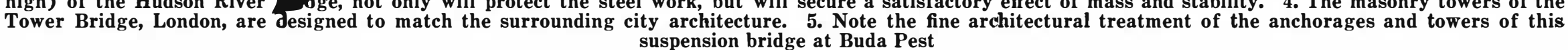


fore built with an exaggerated regard for economy, so that they provided only enough strength to carry safely the prescribed loads, in most cases without sufficien margin for future increase of loading. As the weight of trains increased, large, costly bridges were found too weak and had to be replaced with structures of greater strength; but even then, no greater margin of strength was provided for a further increase of loads under the necessities of traffic. These cheese-paring economies have become very costly on all railroads. Because of this lamentable want of foresight, already, on several American railroads there have been four generation of metal bridges. Meanwhile, stone arch bridges have required no such rebuilding. The many thousand metal highway bridges throughout the country are of the same character. In almost all such cases there was and is no thought of architecture, or of durability, or of pride in the art In the fierce commercial competition, the most naked utilitarian considerations are allowed to govern the design for such structures.

The art of steel bridge building, in the great majority of cases, has thus become a commercialized trade which has been prostituted, under the pretense of scientific economy, to the produc

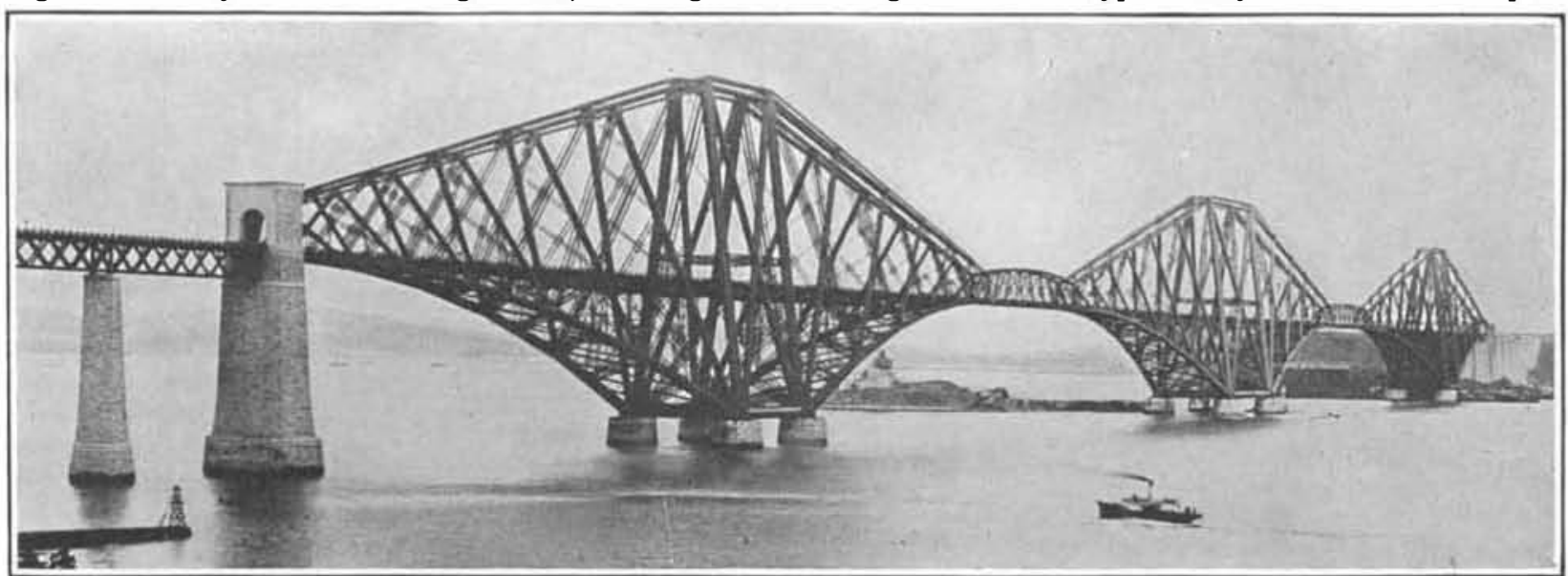

The Forth Bridge, Scotland, with its massive tubular compression members, 12 feet in diameter, and its two quare by over 200 feet high, are built of masonry by necessity, in order to secure the needed mass. The keleten steel towers, were they not clothed in masonry, would look to any but the eye of an engineer entirely too frail, and lacking in dignity for the important duty they have to perform. Considerations of permanence and architectural nobility are the motives which have prompted the clothing of these huge towers in their mantles of enduring granite.

\section{A New Theory of Flight}

AFRMAN inventor, Gustav Lilienthal, has been A studying for some years the wing structure of 1710-foot main spans, gives an impression of strength and permanence surrounding air of the carefully closed room. From a study of the longitudinal profile of the frigate bird it can very readily be seen that the portions of the wing adjacent to the middle portion of the wing from the "shoulder" to the "elbow" and from the "wrist" to the tip have an oblique direction with respect to the lateral current. Because of this fact the kite principle comes into operation and an upward impulse s created.

Lilienthal next built a new model representing an entire bird and imitating the longitudinal profile of the frigate bird wing. In this the motion of the pennants showed that the vortex of air slowed off toward the body and toward the tips. Especially toward the tips the current of air was so strong that even at the ends the pennants flew out in the longitudinal direction of the wings. In other words, directly-cross-wise. The direction of the pressure of the air resistance upon the root and the tip of the wing is therefore no longer slantwise toward the rear, but rotated at a right angle in the longitudinal direction of the wind. Hence there is no longer resistant direction of force, but only the buoyant impulse. In the middle of the wing where the current of air presses tion of the cheapest structures that will carry the loads Even so, we witnessed a few years ago the collapse, merely under its own load, of one of the greatest cantilever bridges ever attempted.

As a matter of fact, supposing that two bridges for let us say, a river crossing are designed with equal strength, one of them with the strictest regard for economy and the other designed not only with regard to economy but also with an eye to its fine architectura appearance, it will be found that the cost of giving beauty and dignity to the bridge is insignificant compared with the total cost of the whole structure.

of late years, engineers have increasingly realized the necessity of providing for the durability of their bridges by encasing their steelwork, as far as possible, in masonry or other nonerodible material. A notable case of this is the Tower Bascule Bridge across the Thames, London. Here, not only was an outer wall of protective masonry built around the main steel towers, but this masonry was designed to harmonize with the ar chitecture of the immediate surroundings of the bridge. The result, from the architectural standpoint, is highly successful, and the Gothic towers harmonize pleasingly with the suspension trusses, the roadways and the bascule portions of the main fior. If of the main in paint ing as much of the steelwork of this bridge as is exposed, there is no reason why its life should not run into the thou sands of years.

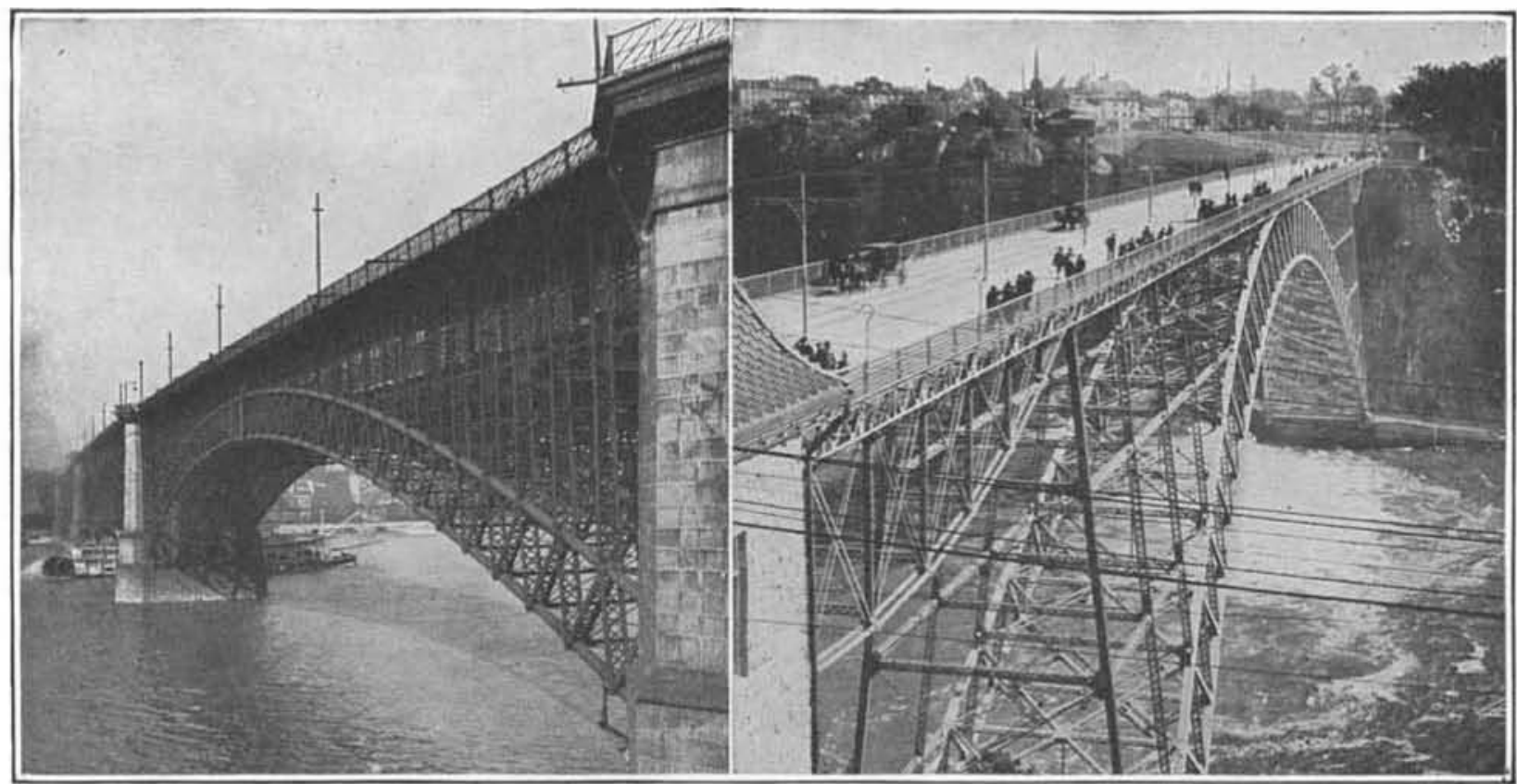

Left: The famous Eads steel arch bridge at St. Louis, a handsome design with appropriate masonry piers and abutments. Right: Beautiful arch roadway bridge of 840-foot span across the Niagara River
He remarks: "Since the bird without any expenditure of energy not only lifts its own weight but is also stil driven forward, it seems certain that if we can discover we shall have gained information very useful with respect to the driving of air craft. By means of the propeller the motor creates an exclusively forward drive to overcome the backward pressure acting upon the airplane. These pressures are produced by the combination of the head resistance of the body of the craft and the rearward slanting pressure of the lifting impulse beneath the wings. If we could find a way to eliminate these resistances, we should at once be able to lower the required power of the motor."

countless experiments and observations extending strongly against the downward bent forward edge of the wing, the direction of the pressure is inclined forward. At this point the driving impulse is entirely forward. On the upper surface of the wing a suction begins to be exerted, but the direction of this lifting force cannot be exactly determ
his models to fresh sea breezes.

As he had expected, his planes and models were subjected to a remarkably strong upward drive-so that not only the head resistance of the forward edge was overcome, but the freely movable experimental planes were moved in front of the plumb line. The excess of the forward impulse over the head resistance needs be but slight, since it produces a constant acceleration. but slight, since it produces a constant acceleration.
The largest model had a wing surface of 30 sq. m. It was observed in these large models that there was a backward bow of air under the tail also. In the case of real birds this currentof air strikes the soft plumage of the body and thus over comes the head resistance of the latter.

The experimenter concludes that when the wind lacks the "friction buoyancy" birds are as unable to soar as they are in a dead calm; even if the bird had acquired a great forward velocity by means of beating 1 ts wings and volplaning, it would still be unable to soar. In both cases it would lack the source of energy given by the buoyant impulse without which source no work could be done.

Lilienthal does not hesitate to declare that the

The latest notable recognition of the call for permanence in costly bridge structures, and for architectural effects which will express the main constructional feature of a bridge, is the North River Bridge across the Hudson River, New York, which, because of its vast size and monumental character, to say nothing of its urgent utility in the transportation problem of the metropolis-calls loudly both for architectural dignity and the assurance of permanent life.

The principal elements in this structure are the cables and the towers. The preservation of these will be met by encasing the cables in continuous bronze or copper tubes impervious to the weather, and in the case of the towers by clothing them with walls of masonry throughout their entire height. The huge anchorages, 400 feet over a period of many years, into whose details we cannot well go, led Lilienthal to construct an artificia plane having a cross section similar to the middle par of that of the wing of a frigate bird. The plane wa first placed in a room carefully protected from externa air currents and set in rapid motion, the direction of the currents thus produced being shown by small pennants placed on the upper and the lower sides of the frame. On the upper side of the plane the current of air followed the curvature of the profile exactly, whereas on the under side of the plane a vortex was produced, in such a manner that the air flowed along the under side of the plane from back to front whereupon the spirals of the vortex wound themselves outward like the horns of a ram and flowed off right and left into or which we are indebted to Kosmos (Stuttgart) for April, 1921, is destined to be the form of the future airplane.

\section{Bitumen in Palestine}

BITUMFN is gathered in Palestine from the Dead Sea, where it is found floating on the surface of the sea. Prior to the war this bitumen was gathered and turned over to an American, who lived in Jerusalem, who in turn exported it by special permit. It is said that the annual ort amounted to approximately 50 tons, and that pracam lly entire output was sent to Germany, where it was used in preparing the glos for patent leather. At present very little of this bitu men is being gathered. 